Provided for non-commercial research and education use. Not for reproduction, distribution or commercial use.

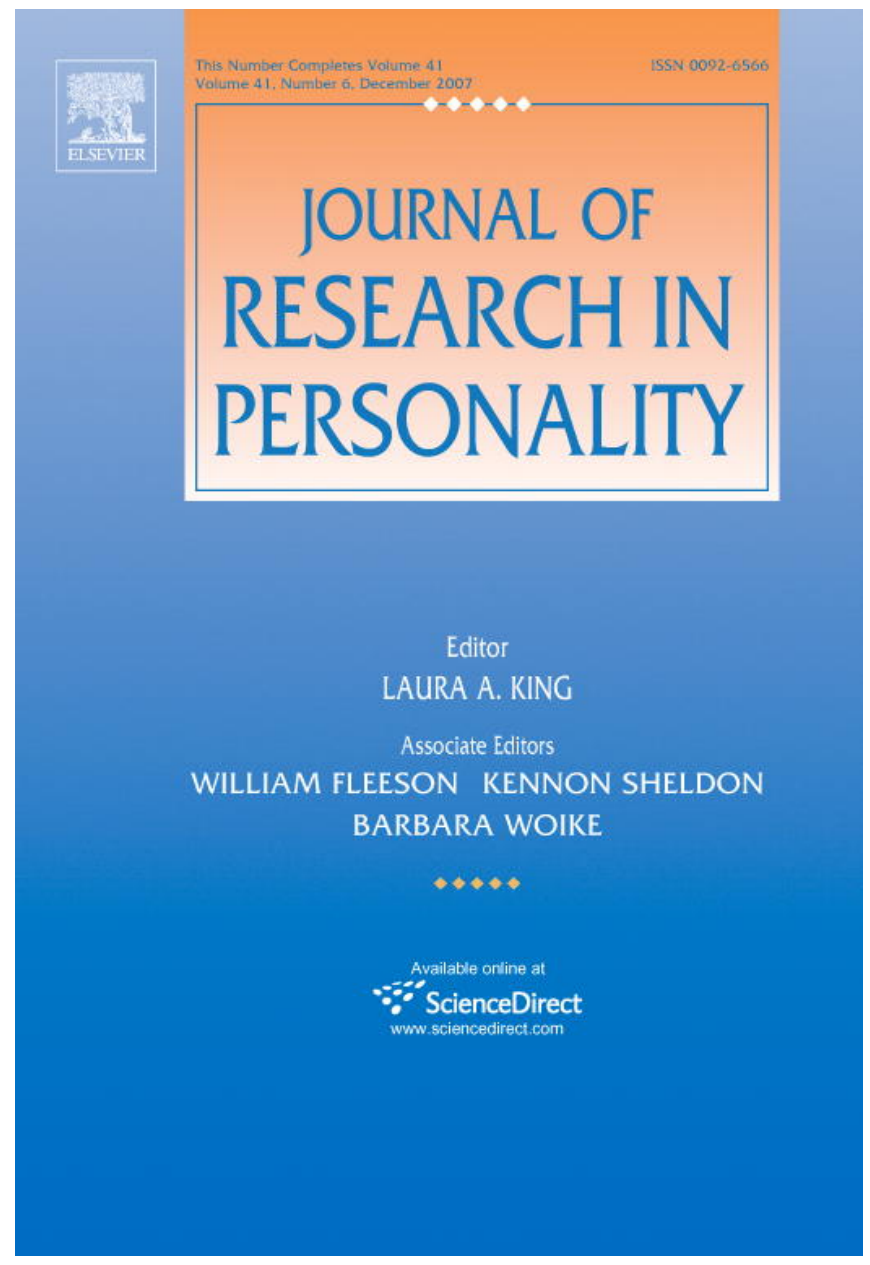

This article was published in an Elsevier journal. The attached copy

is furnished to the author for non-commercial research and education use, including for instruction at the author's institution, sharing with colleagues and providing to institution administration.

Other uses, including reproduction and distribution, or selling or licensing copies, or posting to personal, institutional or third party websites are prohibited.

In most cases authors are permitted to post their version of the article (e.g. in Word or Tex form) to their personal website or institutional repository. Authors requiring further information regarding Elsevier's archiving and manuscript policies are encouraged to visit:

http://www.elsevier.com/copyright 


\title{
The interpersonal meaning of sexual promiscuity
}

\author{
Patrick M. Markey ${ }^{\mathrm{a}, *}$, Charlotte N. Markey ${ }^{\mathrm{b}}$ \\ ${ }^{a}$ Department of Psychology, Villanova University, 800 Lancaser Avenue, Villanova, PA 19085, USA \\ ${ }^{\mathrm{b}}$ Department of Psychology, Rutgers University, 311 N. 5th Street, Camden, NJ, 08102, USA
}

Available online 6 March 2007

\begin{abstract}
In order to investigate the interpersonal meaning of sexual promiscuity, the relations between various sexual activities and the Interpersonal Circumplex (IPC) were examined. Two hundred and ten participants ( 105 women and 105 men; mean age $=24.88$ years) indicated the number of people they had engaged in various sexual activates with (e.g., oral manipulation of genitals, sexual intercourse, etc.). These participants' interpersonal styles were also assessed using the primary dimensions of the IPC: dominance and warmth. As predicted, a positive linear relation was found, for men and women, between interpersonal dominance and the number of partners a person had for each type of sexual activity. Additionally, for both men and women, a curvilinear relation was found between interpersonal warmth and the number of partners a person had for each type of sexual activity. Specifically, participants who were either extremely warm or extremely cold tended to have more sexual partners than individuals who were moderately warm. These findings extend past research linking the Five Factor Model traits of extraversion and agreeableness to sexual promiscuity and also help illustrate the dual interpersonal meaning of sexual experience.
\end{abstract}

(C) 2007 Elsevier Inc. All rights reserved.

Keywords: Interpersonal Circumplex; Sexual promiscuity; Five Factor Model

"Sex is a conversation carried out by other means."- - Peter Ustinov

"Sex with love is the greatest thing in life. But sex without love - that's not so bad either."-Mae West

\footnotetext{
* Corresponding author.

E-mail address: patrick.markey@villanova.edu (P.M. Markey).
} 


\section{Introduction}

It is clear that people exercise different amounts of discretion when deciding how many sexual partners to become involved with across their life. Some "save themselves" for marriage while others live their life like a character on the television show Sex and the City. What accounts for different people's willingness (or lack thereof) to engage in sexual relations with multiple partners? Although both research and common sense suggest that individuals' background, including their religious and cultural upbringing, might account for some of this variability (e.g., Francoeur \& Noon, 2004; Rose et al., 2005; Seidman, Mosher, \& Aral, 1992), other factors warrant empirical examination as well. Given that sex is an interpersonal interaction, it seems likely that one's own interpersonal style might be related to sexual promiscuity. For example, a person who is interpersonally cold may have many sexual partners in an attempt to seek out as much self pleasure as possible without regard for their partners' feelings. However, a person who is interpersonally warm might have many sexual partners in an attempt to express his or her warmth and give pleasure to as many other people as possible. The present study examines the interpersonal meaning of sexual promiscuity by using the Interpersonal Circumplex to predict patterns of sexual behaviors.

Examining sexual promiscuity is interesting because, as an interpersonal behavior, sex is a complex behavior that often has different meanings for different people. Some might view sexual promiscuity as an expression of sexual freedom, others might view it as a moral flaw, and some might simply be promiscuous to obtain as much physical pleasure as possible. Additionally, unlike most other interpersonal behaviors, sex is a behavior that can have unwanted consequences. Promiscuous sex with multiple partners increases the likelihood of unintended pregnancy and sexually transmitted diseases (STDs), including HIV infection. The Centers for Disease Control and Prevention (CDC, 2006) has estimated that 19 million STD infections occur annually. In addition to potentially severe health consequences including death, STDs pose a tremendous economic burden with medical costs as high as 15.5 billion dollars in a single year (CDC, 2006). Thus, understanding predictors of promiscuous sex has implications for health education and intervention efforts aimed at improving safe sex behaviors and reducing the risk of STD infection.

Recognizing the importance of predicting sexual behaviors, researchers have found that certain personality qualities may "predispose" individuals to participation in these behaviors (e.g., Hoyle, Fejfar, \& Miller, 2000; John, Caspi, Robins, Moffitt, \& Stouthamer, 1994; Markey, Markey, \& Tinsley, 2003; Markey, Markey, Ericksen, \& Tinsley, 2006). For example, high sensation seekers have been found to engage in a greater variety of sexual activities with more partners than low sensation seekers (Zuckerman, Tushup, \& Finner, 1976). A recent meta-analysis by Bogg and Roberts (2004) suggests that unconscientious individuals tend to have more sexual partners and are less likely to use condoms during sex than conscientious individuals. Further, Eysenck $(1971,1976)$ has found that extraverts are more likely to have higher rates of sexual activity and have more positive attitudes about having multiple sex partners than introverts. Similarly, research has also suggested that individuals low in agreeableness (i.e., antagonistic individuals) are more likely to have multiple sex partners (Miller et al., 2004), engage in HIV risk behaviors (Trobst, Herbst, Masters, \& Costa, 2002), have sex while intoxicated (Miller et al., 2004), and are more willing to engage in sex outside of a committed relationship (Wright \& Reise, 1997) than agreeable individuals. Consistent with these findings, recent 
cross-cultural research from the International Sexuality Description Project, a study examining over 16,000 participants from 52 nations, found that in most regions of the world people who were extraverted and antagonistic tended to be more sexually promiscuous than other individuals (Schmitt, 2004).

Although such noteworthy research helps identify individuals who may be sexual promiscuous and lends some insight into the interpersonal nature of sexual promiscuity, no studies to date have linked sexual promiscuity to what is arguably the most popular model of interpersonal behavior (Hofsess \& Tracey, 2005): the Interpersonal Cirucmplex (IPC). The IPC was originally created by researchers at the Kaiser Foundation (Freedman, Leary, Ossorio, \& Coffey, 1951; LaForge \& Suczek, 1955; Leary, 1957) by systematically observing the interpersonal styles of adults during social interactions. The IPC model presented in Fig. 1 indicates that interpersonal behaviors or styles can be arranged on the circumference of a circle using the primary dimensions of dominance and warmth. This circular ordering suggests that interpersonal styles that fall close together are more positively related than styles that fall further apart, interpersonal styles at right angels are unrelated, and styles opposite each other are negatively related. The two-dimensional structure provided by the IPC has been shown to be a valid predictor of numerous interpersonal constructs and risky behaviors (e.g., Horowitz, 1996; Madison, 1997; Markey, Funder, \& Ozer, 2003; Markey \& Kurtz, 2006; Markey, Markey, \& Tinsley, 2005; Pincus \& Wilson, 2001; Sadler \& Woody, 2003; Tracey, 2004; Trobst, Ayearst, \& Salekin, 2004).

The structure of the IPC suggests that the eight interpersonal styles arranged around the circle can be conceptualized as different "blends" of dominance and warmth. For example, agreeableness is a blend of submission and warmth; whereas extraversion is a blend of dominance and warmth. In fact, past research suggests that the IPC dimensions

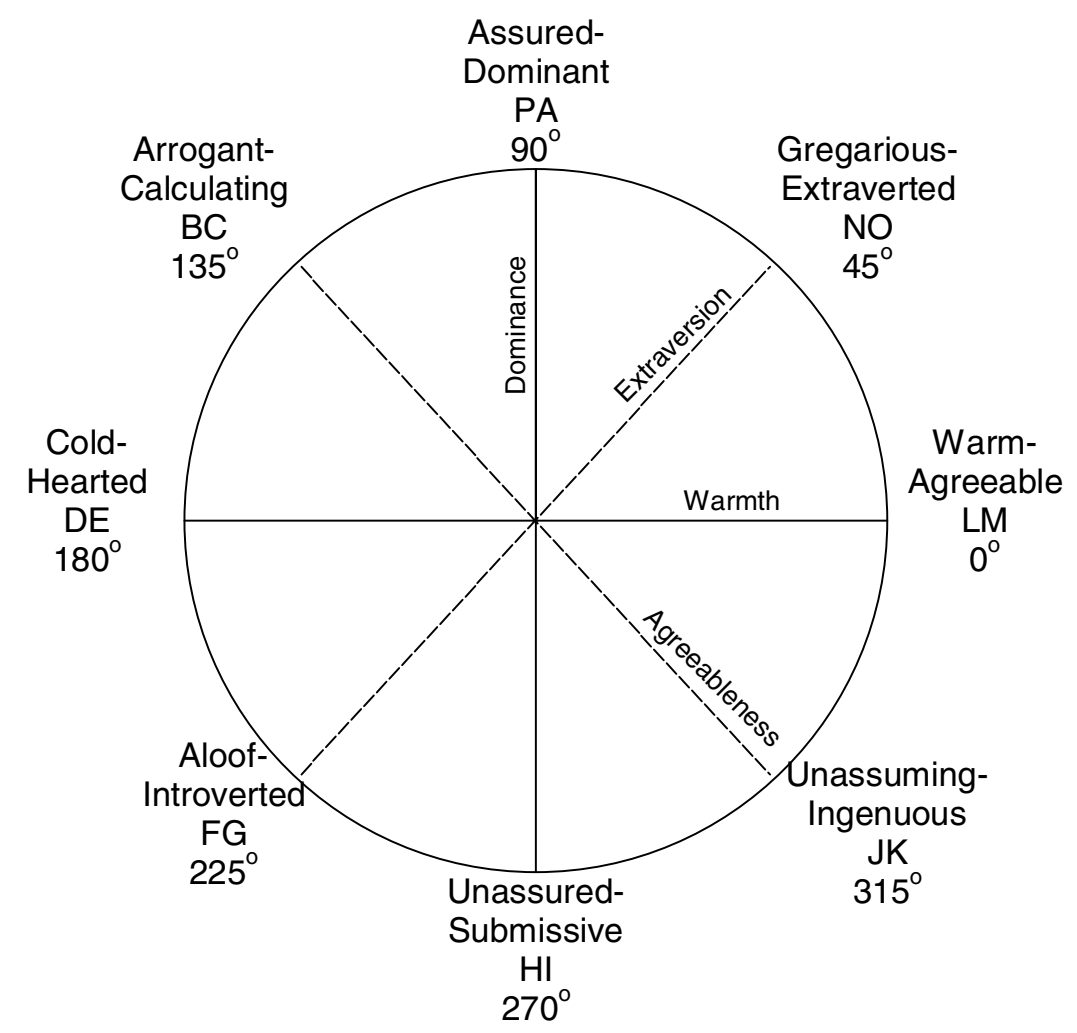

Fig. 1. The Interpersonal Circumplex. 
of warmth and dominance represent approximate $45^{\circ}$ rotations of the Five-Factor Model dimensions of extraversion and agreeableness (see Fig. 1; Markey \& Markey, 2006; McCrae \& Costa, 1989). In this manner, the IPC provides a useful elaboration of two traits past research has repeatedly related to sexual promiscuity: extraversion and agreeableness (e.g., Eysenck, 1971, 1976; Markey et al., 2003; Miller et al., 2004; Trobst et al., 2002; Wright \& Reise, 1997).

Past findings linking extraversion and agreeableness to sexual promiscuity have the potential to be better understood when examined in the context of the IPC. In other words, the IPC may allow unique insight into why past research has linked these traits to sexual promiscuity. For example, since both extraverted (i.e., high dominance and high warmth) and antagonistic (i.e., high dominance and low warmth) individuals tend to be sexually promiscuous, it is likely that interpersonal dominance is an important predictor of sexual promiscuity (i.e., dominant individuals are more sexually promiscuous than submissive individuals). However, past findings are a little less clear as to the significance of interpersonal warmth. It is possible that warmth is simply not predictive of sexual promiscuity and that previous findings linking extraversion and agreeableness to sexual promiscuity occurred because these traits both contain elements of interpersonal dominance. It is equally possible that warmth has a quadratic relation to sexual promiscuity (i.e., both extremely warm individuals and extremely cold individuals tend to be more sexually promiscuous than moderately warm individuals). By simultaneously considering the two IPC dimensions of dominance and warmth the current study examines two potential explanations that account for past findings indicating that extraverted and antagonistic individuals tend to be sexually promiscuous.

Explanation 1: Interpersonal dominance is positively related to sexual promiscuity and interpersonal warmth is unrelated to sexual promiscuity.

Explanation 2: Interpersonal dominance is positively related to sexual promiscuity and interpersonal warmth has a quadratic (i.e., a "U" shaped) relation to sexual promiscuity.

The application of the IPC to sexual promiscuity serves to complement previous research linking extraversion and agreeableness to sexual experience by suggesting why these traits are important predictors. For example, Explanation 1 suggests that extraversion and agreeableness are related to sexual promiscuity simply because they both contain elements of interpersonal dominance. Explanation 2 implies that extraversion and agreeableness are important predictors of sexual promiscuity because they both contain elements of social dominance and they contain opposite elements of interpersonal warmth. Therefore, the results from the current study will not only allow for better identification of who is likely to be sexually promiscuous, but will also help clarify the interpersonal meaning of sexual promiscuity.

\section{Method}

\subsection{Participants and procedures}

Two hundred and ten adults (105 women; 105 men, mean age $=24.88$ years) participated in the present study as part of a larger longitudinal study examining the health 
behaviors of individuals involved in heterosexual relationships. Participants were recruited from a northeastern university campus and surrounding area using flyers and newspaper advertisements. In the sample, $73 \%$ participants reported they were European American/ White, 10\% were African American, 7\% were Asian, 7\% were Hispanic, and 3\% were of an "other" ethnic background. After consenting to participant in the study, participants were reminded that their responses would remain confidential and each participant completed the below questionnaires while seated alone in room. Participants were compensated with $\$ 25.00$, except for $14 \%$ of the sample who were students and elected to be compensated with $2 \mathrm{~h}$ of research credit.

\subsection{Measures}

\subsubsection{Interpersonal style}

In order to assess participants' interpersonal dominance and warmth, participants completed the Interpersonal Adjective Scale (IAS-R; Wiggins, 1995; Wiggins, Trapnell, \& Phillips, 1988). The IAS-R consists of 64 adjective items designed to assess the eight octants of the IPC (see Fig. 1). Past research has demonstrated that the IAS-R conforms to the structure of the IPC (Tracey \& Schneider, 1995; Tracey, Ryan, \& Jaschik-Herman, 2001; Wiggins, 1995). In the current sample, the mean internal consistency estimate of the eight scales was .85 . As is commonly done, the eight octant scales were then used to compute dimensional scores of dominance and warmth for each participant (Wiggins, 1995).

Using the IAS-R dimensional scores of dominance and warmth it is possible to classify an individual's interpersonal style by both its angular location and vector length (VL; Wiggins \& Broughton, 1991). An individual's angular location serves to categorize a person into one of the eight octants of the IPC. The VL corresponds to how far a person falls from the center of the circle (typically in standard deviation units), representing the extremity of his or her interpersonal style. This extremity can range from moderate and flexible (i.e., close to the center of the IPC) to extreme and inflexible (i.e., far from the center). The below formulas can be applied in order to compute an individual's angular location and VL.

Angular Location $\left._{\mathrm{i}}=\operatorname{arctangent}_{\left(Z_{\text {dominance }} / Z_{\text {Zwarmth }}\right)}\right)$

Vector Length L $_{\mathrm{i}}=\left[\left(\left(\text { Zdominance }_{\mathrm{i}}\right)^{2}+\left(\text { Zwarmth }_{\mathrm{i}}\right)^{2}\right)\right]^{1 / 2}$

Where:

Angular Location $_{i}$ is the angular location of the ith person

Vector Length is $_{\mathrm{i}}$ the vector length of the ith person

Zdominance $_{i}$ is the standardized dominance score of the ith person

Zwarmth $_{\mathrm{i}}$ is the standardized warmth score of the ith person

For example, using the above formulas, a fictitious person who is submissive (e.g., Zdominance $=-.90$ ) and interpersonally cold (e.g., Zwarmth $=-.96$ ) would have a VL of 1.31 and an angular score of $223^{\circ}$ classifying him or her as aloof-introverted (i.e., between $202.5^{\circ}$ and $247.5^{\circ}$ ).

\subsubsection{Sexual promiscuity}

To obtain an assessment of participants' sexual promiscuity, each participant completed a modified version of Bentler's Heterosexual Behavioral Inventory (BHBI; Bentler, 1968a, 1968b). The original version of the BHBI contains a list of sexual activities that the 
respondent may have had other people perform on them (e.g., "Oral manipulation of your nude genitals") and behaviors the respondent may have performed on others (e.g., "Oral manipulation of partner's nude genitals"). Although both types of activities are interesting, the current study's main aim was to map the sexual activities a person does (not the behaviors done to him or her) onto the IPC. Therefore, four activities were selected that represented behaviors a respondent would perform on a partner and that were applicable to both men and women. Additionally, these four activities represent different levels of sexual intimacy ranging from kissing to sexual intercourse. These activities were: (1) One minute continuous lip kissing, (2) Manual manipulation of nude partner's genitals, (3) Oral manipulation of nude partner's genitals, and (4) Sexual intercourse, face to face. For each sexual activity, participants were asked to indicate how many different people with which they had engaged in that activity.

\section{Results}

In order to determine if either Explanation 1 or Explanation 2 accurately represents the relation between the IPC and sexual promiscuity, two analyses were conducted for each sexual activity. Specifically, the first analysis examined whether or not warmth was related to each sexual activity in a linear or quadratic manner and the second analysis examined whether or not dominance was related to each sexual activity in a linear manner. Explanation 1 predicts that sexual activity will be unrelated to warmth and will have a linear relation to dominance. In contrast, Explanation 2 predicts sexual activity will have a quadratic relation to warmth and a linear relation to dominance. Finally, the regression equations suggested by the above analyses were computed and used to create a graphical representation of the empirical relations between each sexual activity and the IPC.

To examine if the dimensional score of warmth predicted sexual activities five regression models were hierarchically tested. Model 1 ( sexual activity $=$ constant + gender + error) simply examines whether or not there is a main effect of gender (e.g., do men report higher levels of sexual activity than women?) in order to control for this possible effect in subsequent analyses. Model 2 (sexual activity $=$ constant + gender + warmth + error) examines whether or not there is a linear relation between warmth and sexual activity. Model 3 (sexual activity $=$ constant + gender + warmth + warmth $^{2}+$ error $)$ seeks to determine whether or not there is a quadratic relation between warmth and sexual activity. The remaining models examine whether or not gender moderates either the linear (Model 4; sexual activity $=$ constant + gender + warmth + warmth $^{2}+$ gender $*$ warmth + error) or quadratic (Model 5; sexual activity $=$ constant + gender + warmth + warmth $^{2}+$ gender $*$ warmth + gender $*$ warmth $^{2}+$ error) relations between warmth and sexual activity.

Results from these analyses are presented in Table 1 . In these analyses, gender was dummy coded (women $=0$; men $=1$ ) and warmth was centered. As seen in this table, there was a main effect of gender for every sexual activity except kissing (Model 1). On average, men reported higher levels of sexual activity than women. Additionally, Model 2 shows a significant negative linear relation between warmth and each of the sexual activities. However, Model 3 indicates that the relation between warmth and sexual activity is best represented with a quadratic trend. Additionally, Models 4 and 5 indicate that this quadric trend is similar for both men and women. It therefore appears that, for women and men, the relation between warmth and sexual promiscuity is best described with a quadratic relation. In order to better understand the meaning of this quadratic trend, 
Table 1

Hierarchical regression analyses predicting each sexual activity from interpersonal warmth

\begin{tabular}{|c|c|c|c|c|}
\hline & B & SE & Beta & Increment to $R^{2}, F$, numerator df \\
\hline \multicolumn{5}{|l|}{ One minute continuous lip kissing } \\
\hline M1: Gender & & & & $.02,3.40,1 \mathrm{df}$ \\
\hline Intercept & 9.92 & & & \\
\hline Gender $(\mathrm{G})$ & 4.96 & 2.70 & .12 & \\
\hline M2: G + Warmth & & & & $.02,5.63^{*}, 1 \mathrm{df}$ \\
\hline Warmth (W) & -2.95 & 1.24 & $-.17^{*}$ & \\
\hline M3: $G+W+W^{2}$ & & & & $.03,5.73^{*}, 1 \mathrm{df}$ \\
\hline $\mathrm{W}^{2}$ & 1.73 & .71 & $.19^{*}$ & \\
\hline $\mathrm{M} 4: \mathrm{G}+\mathrm{W}+\mathrm{W}^{2}+\mathrm{G} \times \mathrm{W}$ & & & & $.00, .41,1 \mathrm{df}$ \\
\hline $\mathrm{G} \times \mathrm{W}$ & -1.74 & 2.73 & -.07 & \\
\hline M5: $\mathrm{G}+\mathrm{W}+\mathrm{W}^{2}+\mathrm{G} \times \mathrm{W}+\mathrm{G} \times \mathrm{W}^{2}$ & & & & $.00, .20,1 \mathrm{df}$ \\
\hline $\mathrm{G} \times \mathrm{W}^{2}$ & -.88 & 1.93 & -.09 & \\
\hline \multicolumn{5}{|c|}{ Manual manipulation of nude partner's genitals } \\
\hline M1: Gender & & & & $.06,13.23^{* *}, 1 \mathrm{df}$ \\
\hline Intercept & 3.28 & & & \\
\hline Gender $(\mathrm{G})$ & 4.61 & 1.27 & $.25^{* *}$ & \\
\hline M2: G + Warmth & & & & $.02,4.38^{*}, 1 \mathrm{df}$ \\
\hline Warmth (W) & -1.23 & .59 & $-.15^{*}$ & \\
\hline M3: $\mathrm{G}+\mathrm{W}+\mathrm{W}^{2}$ & & & & $.05,11.82^{* *}, 1 \mathrm{df}$ \\
\hline $\mathrm{W}^{2}$ & 1.16 & .33 & $.26^{* *}$ & \\
\hline $\mathrm{M} 4: \mathrm{G}+\mathrm{W}+\mathrm{W}^{2}+\mathrm{G} \times \mathrm{W}$ & & & & $.00, .12,1 \mathrm{df}$ \\
\hline $\mathrm{G} \times \mathrm{W}$ & -.45 & 1.28 & -.04 & \\
\hline M5: $\mathrm{G}+\mathrm{W}+\mathrm{W}^{2}+\mathrm{G} \times \mathrm{W}+\mathrm{G} \times \mathrm{W}^{2}$ & & & & $.00, .29,1 \mathrm{df}$ \\
\hline $\mathrm{G} \times \mathrm{W}^{2}$ & .49 & .91 & .11 & \\
\hline \multicolumn{5}{|c|}{ Oral manipulation of nude partner's genitals } \\
\hline M1: Gender & & & & $.05,11.80^{* *}, 1 \mathrm{df}$ \\
\hline Intercept & 2.58 & & & \\
\hline Gender $(\mathrm{G})$ & 3.62 & 1.05 & $.23^{* *}$ & \\
\hline M2: G + Warmth & & & & $.02,5.27^{*}, 1 \mathrm{df}$ \\
\hline Warmth (W) & -1.12 & .49 & $-.16^{*}$ & \\
\hline M3: $G+W+W^{2}$ & & & & $.03,7.23^{* *}, 1 \mathrm{df}$ \\
\hline $\mathrm{W}^{2}$ & .76 & .28 & $.21^{* *}$ & \\
\hline $\mathrm{M} 4: \mathrm{G}+\mathrm{W}+\mathrm{W}^{2}+\mathrm{G} \times \mathrm{W}$ & & & & $.00, .02,1 \mathrm{df}$ \\
\hline $\mathrm{G} \times \mathrm{W}$ & .17 & 1.06 & .02 & \\
\hline M5: $\mathrm{G}+\mathrm{W}+\mathrm{W}^{2}+\mathrm{G} \times \mathrm{W}+\mathrm{G} \times \mathrm{W}^{2}$ & & & & $.00, .01,1 \mathrm{df}$ \\
\hline $\mathrm{G} \times \mathrm{W}^{2}$ & .05 & .75 & .01 & \\
\hline \multicolumn{5}{|l|}{ Sexual intercourse } \\
\hline M1: Gender & & & & $.05,10.11^{* *}, 1 \mathrm{df}$ \\
\hline Intercept & 3.06 & & & \\
\hline Gender $(\mathrm{G})$ & 3.60 & 1.13 & $.21^{* *}$ & \\
\hline M2: G + Warmth & & & & $.02,4.05^{*}, 1 \mathrm{df}$ \\
\hline Warmth (W) & -1.06 & .52 & $-.14^{*}$ & \\
\hline M3: $\mathrm{G}+\mathrm{W}+\mathrm{W}^{2}$ & & & & $.02,3.83^{*}, 1 \mathrm{df}$ \\
\hline $\mathrm{W}^{2}$ & .60 & .30 & $.16^{*}$ & \\
\hline $\mathrm{M} 4: \mathrm{G}+\mathrm{W}+\mathrm{W}^{2}+\mathrm{G} \times \mathrm{W}$ & & & & $.00, .54,1 \mathrm{df}$ \\
\hline $\mathrm{G} \times \mathrm{W}$ & .86 & 1.16 & .08 & \\
\hline M5: $\mathrm{G}+\mathrm{W}+\mathrm{W}^{2}+\mathrm{G} \times \mathrm{W}+\mathrm{G} \times \mathrm{W}^{2}$ & & & & $.00, .68,1 \mathrm{df}$ \\
\hline $\mathrm{G} \times \mathrm{W}^{2}$ & -.69 & .83 & -.17 & \\
\hline
\end{tabular}

$n=210$.

${ }^{*} p<.05$.

${ }^{* *} p<.01$. 


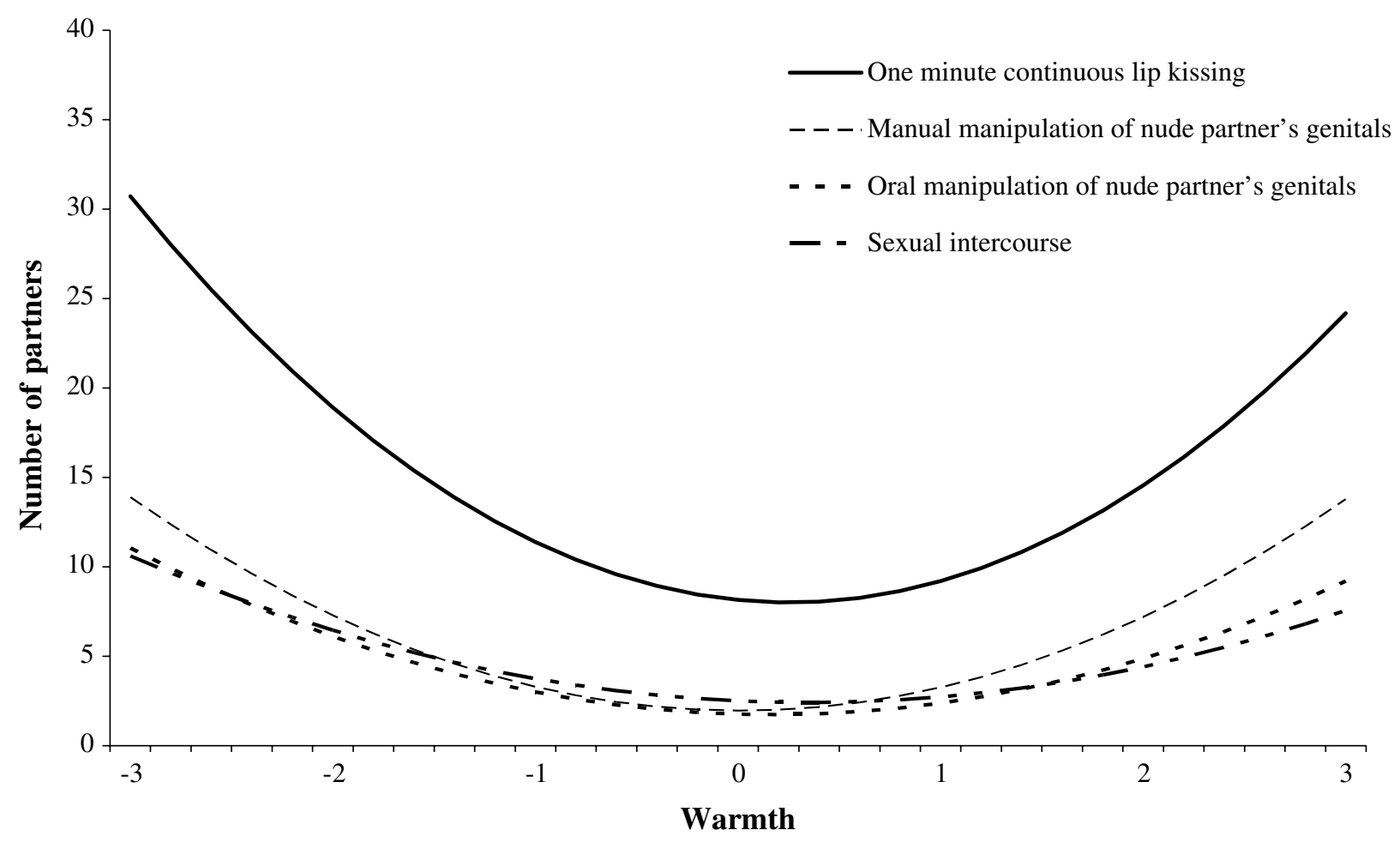

Fig. 2. Graphical display of the quadratic relation between women's sexual promiscuity and interpersonal warmth.

Fig. 2 graphs the relation between warmth and sexual activity for women. As seen in this figure, participants who were either very warm or very cold had more sexual partners than participants with moderate warmth. It should be noted that, because gender did not moderate this relation, the graph for men would be identical except for a slight shift in elevation resulting from the main effect of gender.

Regression analyses were next done to determine if the dimensional score of dominance predicted sexual activities. For each sexual activity, five regression models were again hierarchically tested using dominance instead of warmth. As with warmth, dominance was also centered in these analyses. Results from these analyses are presented in Table 2. As seen in this table, the main effect of gender is again reproduced in Model 1. Model 2 shows a significant positive linear relation between dominance and each of the sexual activities. Additionally, Models 3, 4, and 5 all fail to significantly contribute to the prediction of sexual activity beyond Model 2. It therefore appears that, for women and men, the relation between dominance and sexual promiscuity is best described with a positive linear relation.

The above findings indicate that interpersonal dominance was positively related to sexual promiscuity and warmth had a quadratic relation with sexual promiscuity. Although such regression analyses are revealing, a graphical representation of the relations between each sexual activity and each of the IPC octants should also be informative. Such graphical representations allow for the simultaneous examination of the linear relation of dominance to sexual promiscuity and the quadratic relation of warmth to sexual promiscuity.

In order to graphically represent the relations between sexual activity and the IPC, separate regression equations were first computed for each sexual activity. These four regression equations were consistent with the findings suggesting that sexual promiscuity was related to dominance in a linear manner and was related to warmth in a quadratic manner. 
Table 2

Hierarchical regression analyses predicting each sexual activity from interpersonal dominance

\begin{tabular}{|c|c|c|c|c|}
\hline & B & $\mathrm{SE}$ & Beta & Increment to $\mathrm{R}^{2}, \mathrm{~F}$, numerator $\mathrm{df}$ \\
\hline \multicolumn{5}{|l|}{ One minute continuous lip kissing } \\
\hline M1: Gender & & & & $.02,3.40,1 \mathrm{df}$ \\
\hline Intercept & 9.92 & & & \\
\hline Gender $(\mathrm{G})$ & 4.96 & 2.70 & .12 & \\
\hline M2: G + Dominance & & & & $.04,8.40^{* *}, 1 \mathrm{df}$ \\
\hline Dominance (D) & 4.27 & 1.48 & $.20^{* *}$ & \\
\hline M3: $\mathrm{G}+\mathrm{D}+\mathrm{D}^{2}$ & & & & $.00, .10,1 \mathrm{df}$ \\
\hline $\mathrm{D}^{2}$ & -.37 & 1.16 & -.02 & \\
\hline $\begin{array}{l}\text { M4: } G+D+D^{2}+G \times D \\
\quad G \times D\end{array}$ & .84 & 2.98 & .03 & $.00, .08,1 \mathrm{df}$ \\
\hline $\begin{array}{l}\text { M5: } G+D+D^{2}+G \times D+G \times D^{2} \\
\quad G \times D^{2}\end{array}$ & -1.05 & 2.35 & -.05 & $.00, .20,1 \mathrm{df}$ \\
\hline \multicolumn{5}{|c|}{ Manual manipulation of nude partner's genitals } \\
\hline M1: Gender & & & & $.06,13.23^{* *}, 1 \mathrm{df}$ \\
\hline Intercept & 3.28 & & & \\
\hline Gender $(\mathrm{G})$ & 4.61 & 1.27 & $.25^{* *}$ & \\
\hline M2: G + Dominance & & & & $.03,6.50^{*}, 1 \mathrm{df}$ \\
\hline Dominance (D) & 1.78 & .70 & $.17^{*}$ & \\
\hline$M 3: G+D+D^{2}$ & & & & $.00, .01,1 \mathrm{df}$ \\
\hline $\mathrm{D}^{2}$ & -.02 & .55 & .00 & \\
\hline $\begin{array}{l}\text { M4: } G+D+D^{2}+G \times D \\
\quad G \times D\end{array}$ & .77 & 1.41 & .06 & $.00, .30,1 \mathrm{df}$ \\
\hline $\begin{array}{l}\text { M5: } G+D+D^{2}+G \times D+G \times D^{2} \\
\quad G \times D^{2}\end{array}$ & -.52 & 1.11 & -.05 & $.00, .22,1 \mathrm{df}$ \\
\hline \multicolumn{5}{|c|}{ Oral manipulation of nude partner's genitals } \\
\hline M1: Gender & & & & $.05,11.80^{* *}, 1 \mathrm{df}$ \\
\hline Intercept & 2.58 & & & \\
\hline Gender $(\mathrm{G})$ & 3.62 & 1.05 & $.23^{* *}$ & \\
\hline M2: G + Dominance & & & & $.02,4.94^{*}, 1 \mathrm{df}$ \\
\hline Dominance (D) & 1.30 & .58 & $.15^{*}$ & \\
\hline M3: $G+D+D^{2}$ & & & & $.00, .42,1 \mathrm{df}$ \\
\hline $\mathrm{D}^{2}$ & -.30 & .46 & -.04 & \\
\hline$M 4: G+D+D^{2}+G \times D$ & & & & $.00, .03,1 \mathrm{df}$ \\
\hline $\mathrm{G} \times \mathrm{D}$ & -.22 & 1.18 & -.02 & \\
\hline $\begin{array}{l}\text { M5: } G+D+D^{2}+G \times D+G \times D^{2} \\
\quad G \times D^{2}\end{array}$ & -1.35 & .93 & -.17 & $.01,2.25,1 \mathrm{df}$ \\
\hline \multicolumn{5}{|l|}{ Sexual intercourse } \\
\hline M1: Gender & & & & $.05,10.11^{* *}, 1 \mathrm{df}$ \\
\hline Intercept & 3.06 & & & \\
\hline Gender $(\mathrm{G})$ & 3.60 & 1.13 & $.21^{* *}$ & \\
\hline M2: G + Dominance & & & & $.02,4.10^{*}, 1 \mathrm{df}$ \\
\hline Dominance (D) & 1.27 & .62 & $.14^{*}$ & \\
\hline M3: $G+D+D^{2}$ & & & & $.00, .01,1 \mathrm{df}$ \\
\hline $\mathrm{D}^{2}$ & -.05 & .50 & -.01 & \\
\hline$M 4: G+D+D^{2}+G \times D$ & & & & $.00, .03,1 \mathrm{df}$ \\
\hline $\mathrm{G} \times \mathrm{D}$ & .22 & 1.27 & .02 & \\
\hline M5: $G+D+D^{2}+G \times D+G \times D^{2}$ & & & & $.01, .91,1 \mathrm{df}$ \\
\hline $\mathrm{G} \times \mathrm{D}^{2}$ & -.96 & .99 & -.10 & \\
\hline
\end{tabular}


Fig. 3 displays the resulting regression equations yielded for each type of sexual activity. Next, we computed warmth and dominance scores of hypothetical persons whose angular locations would define them in the center of each IPC octant and who are well defined by that octant (Table 3 presents these values). For the current example, a person was deemed to be well defined by an octant if their VL was 1.5 . For example, persons who are located in the center of the arrogant-calculating octant $\left(135^{\circ}\right)$ with VLs of 1.5 would have a standardized dominance score of 1.06 and a standardized warmth score of -1.06 (these values can be easily confirmed by using the equations presented previously for angular location and VL). Finally, in order to graphically display the regression equations presented in Fig. 3, the values displayed in Table 3 (representing the dominance and warmth scores of individuals clearly defined by each octant) were entered into each regression equation.

One minute continuous lip kissing

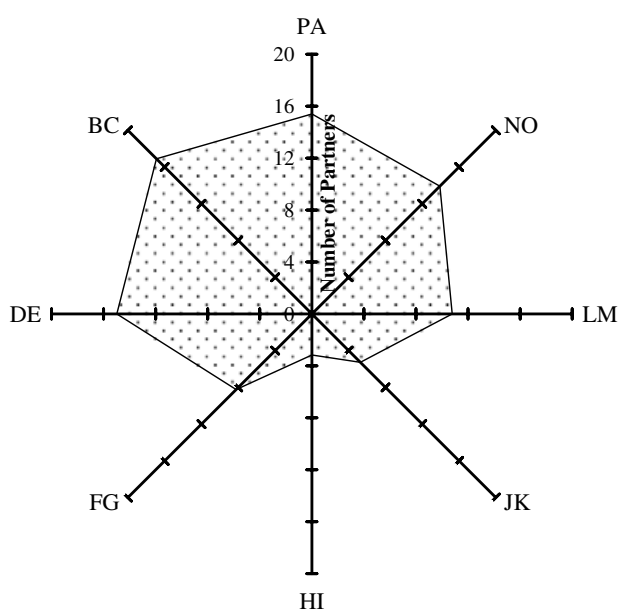

Number of partners $=9.28+2.38(\mathrm{Sex})+\underline{4.08}(\mathrm{Dom})-1.40($ Warm $)+\underline{1.60}\left(\mathrm{Warm}^{2}\right)$

Oral manipulation of nude partner's genitals

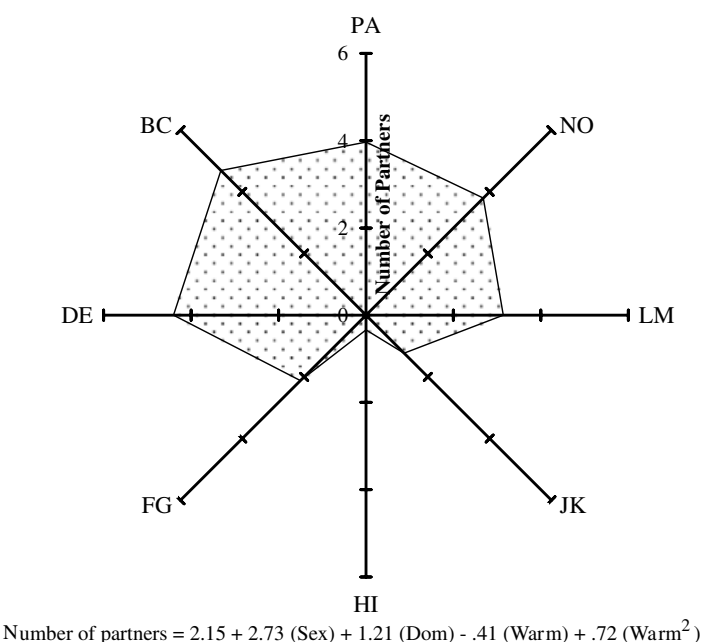

Manual manipulation of nude partner's genitals

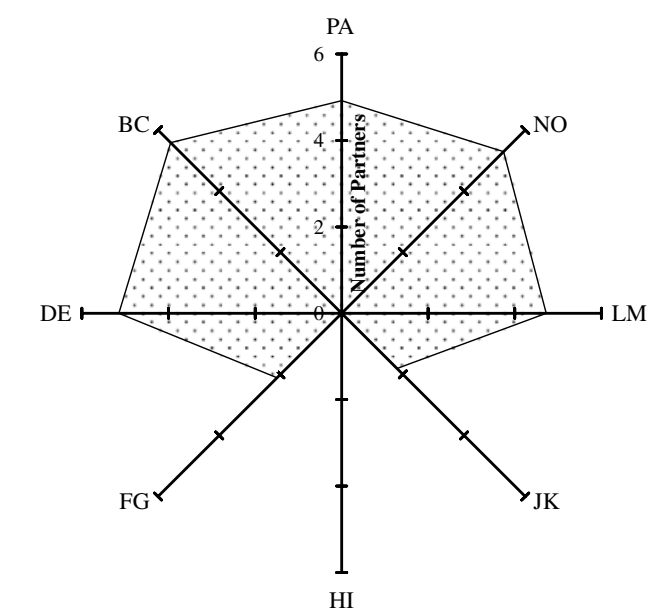

Number of partners $=2.43+\underline{3.60}(\operatorname{Sex})+\underline{1.64}($ Dom $)-.14($ Warm $)+\underline{1.01}\left(\right.$ Warm $\left.^{2}\right)$

Sexual intercourse

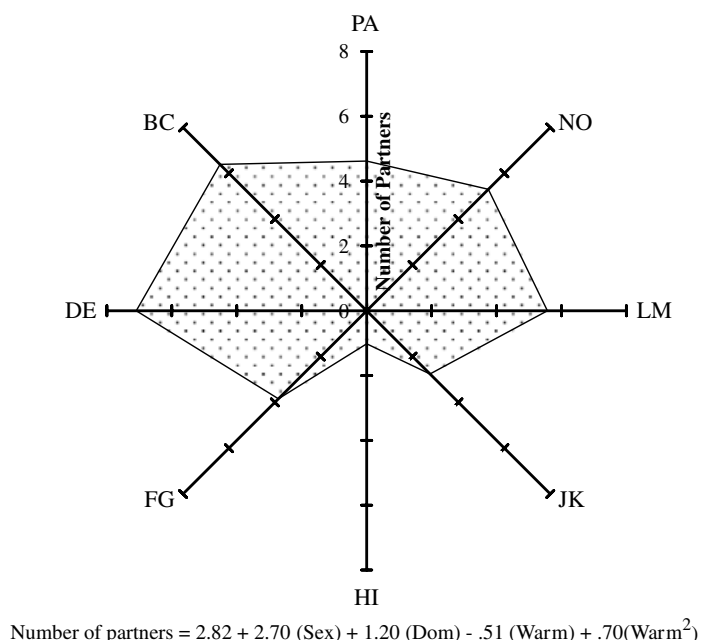

Number of partners $=2.82+\underline{2.70}(\mathrm{Sex})+\underline{1.20}(\mathrm{Dom})-.51(\mathrm{Warm})+\underline{.70}\left(\mathrm{Warm}^{2}\right)$

Fig. 3. Graphical representations of regression equations predicting the number of sexual partners women would have who are well defined (i.e., $\mathrm{VL}=1.50$ ) by an IPC octant. Note: Underlined values indicate a significant $(p<.05)$ regression weight. PA, Assured-Dominant; BC, Arrogant-Calculating; DE, Cold-Hearted; FG, AloofIntroverted; HI, Unassured-Submissive; JK, Unassuming-Ingenuous; LM, Warm-Agreeable; NO, GregariousExtraverted. 
Table 3

The interpersonal dominance and warmth scores of persons whose angular location defines them in the center of each IPC octant and who have VLs of 1.50

\begin{tabular}{llcc}
\hline Octant & Octant label & Dominance score & Warmth score \\
\hline Assured-Dominant & PA & 1.50 & 0.00 \\
Arrogant-Calculating & BC & 1.06 & -1.06 \\
Cold-Hearted & DE & 0.00 & -1.50 \\
Aloof-Introverted & FG & -1.06 & -1.06 \\
Unassured-Submissive & HI & -1.50 & 0.00 \\
Unassuming-Ingenuous & JK & -1.06 & 1.06 \\
Warm-Agreeable & LM & 0.00 & 1.50 \\
Gregarious-Extraverted & NO & 1.06 & 1.06 \\
\hline
\end{tabular}

The eight predicted values yielded from each regression equation are presented in Fig. 3 . Because there were no gender interactions, the profiles presented in Fig. 3 would be similar for men; the only difference would be a mean profile elevation resulting from the gender effects in each equation. As seen in this figure, results for each sexual activity were consistent with Explanation 2 and were also consistent with previous research suggesting that extraverted and antagonistic individuals (i.e., octants $\mathrm{NO}$ and $\mathrm{BC}$, respectively) tend to be more sexually promiscuous than introverted or agreeable individuals (i.e., octants FG and JK, respectively).

\section{Discussion}

Using the IPC, the current research examined two different explanations that could account for past research linking extraversion and agreeableness to sexual promiscuity. As indicated by the regression analyses and Fig. 3, interpersonal dominance was positively related to sexual promiscuity and warmth had a quadratic relation with sexual promiscuity. This finding consistently occurred across each sexual activity (i.e., One minute continuous lip kissing, manual manipulation of nude partner's genitals, oral manipulation of nude partner's genitals, and sexual intercourse) that was examined. Thus, consistent with Explanation 2, individuals in this sample who were dominant and were either very cold or very warm were more likely to have multiple sexual partners than were other individuals.

The above findings help clarify why previous research has tended to find that extraverted and antagonistic individuals are likely to be sexually promiscuous. Specifically, it suggests that these individuals are likely to be sexually promiscuous because they are dominant and because they are either very warm (i.e., extraverted individuals) or very cold (i.e., antagonistic individuals). It seems plausible that such dominant individuals are sexually promiscuous because they may not be shy about seeking out partners with whom they can engage in these behaviors, while submissive individuals may wait to be "sought out" and may remain waiting in some cases. The quadratic relation between sexual promiscuity and warmth found in this study is more complex and appears to indicate that people may participate in sexual activities for very different reasons. Given the link between interpersonal coldness and an avoidant attachment style (Gallo, Smith, \& Ruiz, 2003), it is possible that cold individuals tend to have multiple sex partners, while avoiding a long-lasting romantic relationship, out of fear of mistreatment or later rejection from a committed romantic partner (Bartholomew \& Horowitz, 1991). It is equally possible that 
cold individuals are sexually promiscuous because they might view sex as a selfish act and have no problem seeking out as much pleasure as possible without regard for their partner's feelings. In contrast, warm individuals may view sex as a generous act that provides an opportunity to exchange love, intimacy, or friendship with as many people as possible.

\subsection{Limitations}

Although the present study contributes to our understanding of personality qualities that may place individuals at risk for participating in promiscuous sexual behaviors, there are some limitations that warrant mention. First, the present study employed self-report data exclusively. Even though participants were repeatedly assured that their information was anonymous, it is possible, given the personal nature of the questions asked, that some participants were not completely forthcoming with their answers. Of course, a superior alternative means of assessing individuals' past sexual behaviors is not readily available.

Although the current research successfully linked four sexual behaviors to the IPC, it would be interesting to examine a multitude of sexual behaviors in order to better understand the interpersonal meaning of a greater variety of sexual behaviors. Additionally, because participants in the current study were required to be involved in a heterosexual relationship, it is unknown if the findings of the current study would be similar for individuals involved in a homosexual relationship. Finally, the present study is also limited in its use of a somewhat homogenous sample in terms of age and ethnic background. Although the present findings complement findings from cross-cultural research (Schmitt, 2004), future research should continue to explore these issues among diverse samples.

\subsection{Implications}

Understanding interpersonal personality predictors of sexual promiscuity has implications for our understanding of individuals' sexual choices and also their health risks. Although "promiscuity" has a negative connotation to many and implies that an individual "sleeps around" and is casual in their sexual exploits, the present study suggests that this indiscriminate behavior may not always be ill-intentioned, but in some cases may be an expression of warmth. Further, selective participation in sexual behaviors may be a reflection of an individual's submissiveness, not their "moral piety." Of course, regardless of the personal qualities potentially prompting or discouraging sexual promiscuity, promiscuous sexual behavior can be risky. Understanding the combination(s) of interpersonal qualities that predict promiscuity has implications for health promotion and intervention efforts. Identification of individuals who possess qualities that place them at risk for maintaining several sexual partners may lead to progress in helping individuals to change their potentially health-compromising patterns of behaviors.

\section{References}

Bartholomew, K., \& Horowitz, L. (1991). Attachment styles among young adults: A test of a four category model. Journal of Personality and Social Psychology, 61, 226-241.

Bentler, P. M. (1968a). Heterosexual behavior assessment: I. Males. Behavior Research and Therapy, 6, 21-25.

Bentler, P. M. (1968b). Heterosexual behavior assessment: II. Females. Behavior Research and Therapy, 6, 27-30.

Bogg, T., \& Roberts, R. W. (2004). Conscientiousness and health related behaviors: A meta-analysis of the leading behavioral contributors to mortality. Psychological Bulletin, 130, 887-919. 
Centers for Disease Control and Prevention (CDC). (2006). Trends in reportable sexually transmitted diseases in the United States, 2004. Retrieved July 10, 2006 from, <http://www.cdc.gov/std/stats/trends2004.htm/>.

Eysenck, H. J. (1971). Introverts, extraverts, and sex. Psychology Today, 4, 48-51.

Eysenck, H. J. (1976). Sex and personality. London: Open Books.

Francoeur, R. T., \& Noon, R. J. (Eds.). (2004). The Continuum complete international encyclopedia of sexuality: Updated, with more countries. New York: Continuum International Publishing Group.

Freedman, M. B., Leary, T. F., Ossorio, A. G., \& Coffey, H. S. (1951). The interpersonal dimension of personality. Journal of Personality, 20, 143-161.

Gallo, L. C., Smith, T. W., \& Ruiz, J. M. (2003). Attachment style: Circumplex descriptions, recalled developmental experiences, self-representations, and interpersonal functioning in adulthood. Journal of Personality, 71, 141-181.

Hofsess, C. D., \& Tracey, T. J. G. (2005). The Interpersonal Circumplex as a model of interpersonal capabilities. Journal of Personality Assessment, 84, 137-147.

Horowitz, L. M. (1996). The study of interpersonal problems: A Leary legacy. Journal of Personality Assessment, 66, 283-300.

Hoyle, R. H., Fejfar, M. C., \& Miller, J. D. (2000). Personality and sexual risk taking: A quantitative review. Journal of Personality, 66, 1203-1231.

John, O. P., Caspi, A., Robins, R. W., Moffitt, T. E., \& Stouthamer, L. M. (1994). The "little five": Exploring the nomological network of the five-factor model of personality in adolescent boys. Child Development, 65, $160-178$.

LaForge, R., \& Suczek, R. F. (1955). The interpersonal dimension of personality: III. An interpersonal checklist. Journal of Personality, 24, 94-112.

Leary, T. (1957). The interpersonal diagnosis of personality. New York: Ronald.

Madison, J. K. (1997). Interpersonal assessment and therapy of eating disorders: A clinical application of a circumplex model. In R. Plutchik \& H. R. Conte (Eds.), Circumplex models of personality and emotions (pp. 431-446). Washington DC: American Psychological Association.

Markey, P. M., Funder, D. C., \& Ozer, D. J. (2003). Complementarity of interpersonal behaviors in dyadic interactions. Personality and Social Psychology Bulletin, 29, 1082-1090.

Markey, C. N., Markey, P. M., Ericksen, A. J., \& Tinsley, B. J. (2006). Children's behavioral patterns, the fivefactor model of personality, and risk behaviors. Personality and Individual Differences, 41, 1503-1513.

Markey, P. M., \& Kurtz, J. E. (2006). Increasing acquaintanceship and complementarity of behavioral styles and personality traits among college roommates. Personality and Social Psychology Bulletin, 32, 907-916.

Markey, P. M., \& Markey, C. N. (2006). A spherical conceptualization of personality traits. European Journal of Personality, 20, 169-193.

Markey, C. N., Markey, P. M., \& Tinsley, B. J. (2003). Personality, puberty, and preadolescent girls' risky behaviors: Examining the predictive value of the five-factor model of personality. Journal of Research in Personality, 37, 405-419.

Markey, P. M., Markey, C. M., \& Tinsley, B. (2005). Applying the interpersonal circumplex to children's behavior: Parent-child interactions and risk behaviors. Personality and Social Psychology Bulletin, 31, 549-559.

McCrae, R. R., \& Costa, P. T. (1989). The structure of interpersonal traits: Wiggins's circumplex and the fivefactor model. Journal of Personality and Social Psychology, 56(4), 586-595.

Miller, J. D., Lynam, D., Zimmerman, R. S., Logan, T. K., Leukefeld, C., \& Clayton, R. (2004). The utility of the Five Factor Model in understanding risky sexual behavior. Personality and Individual Differences, 36, $1611-1626$.

Pincus, A. L., \& Wilson, K. R. (2001). Interpersonal variability in dependent personality. Journal of Personality, 69, 223-251.

Rose, A., Koo, H. P., Bhaskar, B., Anderson, K., White, G., \& Jenkins, R. R. (2005). The influence of primary caregivers on the sexual behavior of early adolescents. Journal of Adolescent Health, 37, 135-144.

Sadler, P., \& Woody, E. (2003). Is who you are who you're talking to? Interpersonal style and complementarity in mixed-sex interactions. Journal of Personality and Social Psychology, 84(1), 80-96.

Schmitt, D. P. (2004). The Big Five related to risky Sexual behaviour across 10 world regions: Differential personality associations of sexual promiscuity and relationship infidelity. European Journal of Personality, 18, 301-319.

Seidman, S. N., Mosher, W. D., \& Aral, S. O. (1992). Women with multiple sex partners: United States, 1988. American Journal of Public Health, 82, 1388-1394. 
Tracey, T. J. G. (2004). Levels of interpersonal complementarity: A simplex representation. Personality and Social Psychology Bulletin, 30, 1211-1225.

Tracey, T. J. G., Ryan, M., \& Jaschik-Herman, B. (2001). Complementarity of interpersonal circumplex traits. Personality and Social Psychology Bulletin, 27, 786-797.

Tracey, T. J. G., \& Schneider, P. L. (1995). An evaluation of the circular structure of the Checklist of Interpersonal Transactions and the Checklist of Psychotherapy Transactions. Journal of Counseling Psychology, 42, 496-507.

Trobst, K. K., Ayearst, L. E., \& Salekin, R. T. (2004). Where is the personality in personality disorder assessment? A comparison across four sets of personality disorder scales. Multivariate Behavioral Research, $39,231-271$.

Trobst, K. K., Herbst, J. H., Masters, H. L., \& Costa, P. T. (2002). Personality pathways to unsafe sex: Personality, condom use, and HIV risk behaviors. Journal of Research in Personality, 36, 117-133.

Wiggins, J. S. (1995). Interpersonal Adjective Scales professional manual. Odessa, FL: Psychological Assessment Resources.

Wiggins, J. S., \& Broughton, R. (1991). A geometric taxonomy of personality scales. European Journal of Personality, 5, 343-365.

Wiggins, J. S., Trapnell, P., \& Phillips, N. (1988). Psychometric and geometric characteristics of the Revised Interpersonal Adjective Scales (IAS-R). Multivariate Behavioral Research, 23(4), 517-530.

Wright, T. M., \& Reise, S. P. (1997). Personality and unrestricted sexual behavior: Correlations of sociosexuality in Caucasian and Asian college students. Journal of Research in Personality, 31, 166-192.

Zuckerman, M., Tushup, R., \& Finner, S. (1976). Sexual attitudes and experience: Attitude and personality correlates and changes produced by a course in sexuality. Journal of Consulting and Clinical Psychology, 44, $7-19$. 